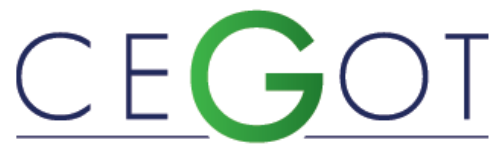

Centro de Estudos de Geografia e Ordenamento do Território
Geografia e Ordenamento do Território, Revista Eletrónica Centro de Estudos de Geografia e Ordenamento do Território http://cegot.org

SOARES, MANUEL

Faculdade de Economia da Universidade de Coimbra 3004-512, Coimbra, Portugal, Avenida Dr. Dias da Silva, 165 manuelpsoares@gmail.com

\section{BRASIL, LUCAS}

Faculdade de Economia da Universidade de Coimbra; Faculdade e Arquitetura e Urbanismo da Universidade de Brasília, Brasil. 3004-512, COIMBRA, PORTUGAL lucasbrasilp@gmail.com

\title{
Impacto da pandemia da Covid-19 nos hábitos de utilização dos parques verdes urbanos: o caso de Condeixa-a-Nova
}

\author{
Impact of the Covid 19 pandemic on urban green space usage patterns: the case of Condeixa-a-Nova
}

Referência: Soares, Manuel; Pereira, Lucas (2020). Impacto da pandemia da Covid-19 nos hábitos de utilização dos parques verdes urbanos: o caso de Condeixa-a-Nova. Revista de Geografia e Ordenamento do Território (GOT), n.o 20 (Dezembro). Centro de Estudos de Geografia e Ordenamento do Território, p. 167-190, dx.doi.org/10.17127/got/2020.20.008

\section{RESUMO}

O presente artigo ambiciona contribuir para o debate acerca da utilização de espaços públicos nas cidades, assumindo como foco a problemática desencadeada pelo contexto da pandemia da covid-19 e suas contingências. A partir do caso do parque verde da Ribeira de Bruscos, em Condeixa-a-Nova, Portugal, reconhece-se a potencialidade de discutir transformações nos usos pré-pandemia e durante o período de afrouxamento das restrições de frequência e permanência nos espaços públicos. Explora-se a possibilidade de o confinamento forçado ter potenciado os níveis de frequência dos espaços verdes urbanos na fase de desconfinamento. Com base num inquérito a uma amostra da população residente de Condeixa-a-Nova, procurou descortinar-se possíveis alterações no comportamento das pessoas que conduziram a uma alteração dos níveis de frequência do parque verde urbano decorrentes da pandemia.

Palavras-chave: Práticas; Covid-19; Confinamento; Parques Verdes Urbanos.

\section{ABSTRACT}

This article aims to contribute to the debate about the use of public spaces in cities, focusing on the problems caused by Covid-19 pandemics and its contingencies. Using the case of the Ribeira de Bruscos urban green park in Condeixa-a-Nova, Portugal, the potential to discuss the changes in use prior to the pandemic and during the period of relaxation of restrictions on the frequency and permanence of public space use is recognized. The possibility that the forced confinement has potentiated the frequency levels of urban green spaces in the phase of deconfinement is explored. Based on a survey of a sample of the resident population of 
Condeixa-a-Nova, an attempt was made to identify possible changes in people's behavior habits that led to a change in the frequency habits of the urban green park due to the pandemic.

Keywords: Practices; Covid-19; confinement; Urban Green parks.

\section{Introdução}

O mundo assiste há muito a um êxodo do campo em direção às cidades, ao ponto de atualmente mais de metade da população mundial habitar já em espaço urbano, estimandose que em 2050 esse valor se cifre acima dos dois terços (United Nations Department of Economic and Social Affairs, 2018), e levantando a hipótese da existência de uma efetiva "urbanização planetária" (Brenner \& Schmid, 2014). Esse grande afluxo de população tem provocado efeitos drásticos quer na paisagem, quer no ambiente das cidades e tem significado não apenas o crescimento físico urbano, mas a expansão das lógicas e impactos oriundos das cidades até mesmo para territórios distantes. Os impactos no ambiente e nos ecossistemas provenientes da expansão da urbanização e de infraestruturas erigidas para acolher e atender milhares de pessoas que, a um ritmo diário, passam a novos citadinos têm constituído uma preocupação cada vez maior, especialmente desde os anos 70, influenciando nas estratégias de planeamento das cidades, emergindo no discurso urbano, a partir dos anos 90, a ideia de sustentabilidade (M. do C. Bezerra, da Rocha, \& Bogniotti, 2016). Mais recentemente, a expressão desses impactos galgou um novo patamar, tornando cada vez mais necessário o reconhecimento de uma nova denominação para a época cujo principal agente de transformação tem sido a humanidade: o Antropoceno.

A inversão verificada em décadas relativamente recentes, que ditou que a humanidade deixasse de ser essencialmente rural para passar a ser urbana, fez com que a realidade vivida nas cidades fosse marcada por um modo de vida citadino com visíveis impactos na vida dos seus habitantes e que se passasse a olhar para os espaços verdes como elemento fundamental para o equilíbrio psicológico dos residentes do urbano (Mattos \& Constantino, 2019). Rapidamente esses espaços tornaram-se lugares para a prática de atividades físicas, descanso ou convívio, com efeitos positivos na qualidade de vida e saúde (Fonseca, Gonçalves, \& Rodrigues, 2010, pp. 121-122). Os benefícios na aposta nos espaços verdes urbanos podem ser agrupados nos domínios ambiental, económico e social (Fonseca et al., 
2010, p. 121) e vão desde a redução dos riscos de saúde associados aos ritmos da vida urbana, passando pelo alívio do stress e pelo relaxamento que a atividade física propicia, até as vantagens decorrentes da interação social que potencialmente abriga, podendo ser especialmente relevantes para os grupos sociais mais desfavorecidos (World Health Organization, 2017, p. 6). Assim, esses locais constituem-se como indicadores de qualidade de vida no espaço urbano e assumem um papel importante enquanto fatores de equidade em cidades marcadas por diferenças sociais e espaciais (Yilmaz \& Mumcu, 2016, p. 101).

A par com a crescente aposta nos espaços verdes em contexto urbano, assiste-se a um certo "viés antropocêntrico", tendo em conta que o "meio ambiente nessa visão é valorado para se chegar ao melhor padrão de vida para o ser humano e não pelo entendimento que se vive em um sistema único e interdependente" (M. do C. Bezerra et al., 2016, p. 130). Parece, portanto, pertinente discutir a problemática relativa à galopante destruição ambiental que a ação humana vem impondo ao meio ambiente em termos globais, para a qual contribui o próprio modo de vida urbano no contexto do modelo capitalista, visto que as cidades são responsáveis direta e indiretamente pela produção de $75 \%$ de todo o gás carbónico lançado na atmosfera e por cerca de $60 \%$ do consumo de recursos (Martin, sem data). Por outro lado, as formas de ocupação dos tempos livres em meio urbano pautam-se pelo interesse por centros comerciais, ginásios, cafés e outros espaços similares em concorrência com os espaços livres, públicos e comuns.

Com a presente crise pandémica provocada pela covid-19, diretamente ligada aos processos antropogénicos, grande parte da população urbana mundial foi obrigada a confinar-se em casa durante várias semanas, tendo-Ihe sido limitados muitos dos movimentos habituais e obrigando ao encerramento de muitos dos espaços de lazer normalmente utilizados. Os impactos em termos físicos e mentais, decorrentes desse confinamento forçado, começam já a motivar estudos, cujos resultados parecem ir no sentido de indicarem maiores níveis de stress e apontarem para uma vontade crescente, resultante da quarentena, pelo regresso ao convívio social (A. Bezerra, da Silva, Soares, \& da Silva, 2020). Neste sentido, a hipótese que aqui é colocada é que o confinamento determinado pela pandemia poderá ter contribuído para uma maior propensão para a utilização dos espaços de lazer verdes 
urbanos, enquadrando esse processo no contexto de uma escala ampliada que reconhece a sua relação com o Antropoceno.

Tomando como objeto de análise o Parque Verde da Ribeira de Bruscos/Sra. das Dores, na vila de Condeixa-a-Nova, nos arredores próximos da cidade de Coimbra, procura explorar-se a hipótese de um aumento de frequência de utilização, tentando perceber se, de facto, o confinamento se constituiu como uma oportunidade para uma maior frequência dos parques verdes urbanos. A análise faz-se de duas formas: num primeiro exercício procedese à comparação fotográfica, com base na observação de imagens registadas em junho de 2019 (pré-pandemia) e no mesmo mês em 2020 (durante a pandemia), procurando verificar alterações na frequência do espaço em questão; numa segunda análise, recorre-se aos resultados de um estudo quantitativo, obtido através de um inquérito a uma amostra da população de Condeixa, para procurar perceber alterações nos padrões de utilização do parque de lazer.

\section{Espaços verdes urbanos/parques verdes urbanos}

No contexto do Antropoceno, diante dos danos ambientais gerados pela ação humana e, principalmente, pelos modos de vida urbanos sob a lógica de um capitalismo expansivo, os espaços verdes têm sido vistos como soluções efetivas para manter a qualidade ambiental urbana, pois absorvem poluição, mantêm os níveis de humidade, contribuem para a precipitação e ajudam a controlar a temperatura, ao mesmo tempo que podem auxiliar a conservar a fauna e flora nas cidades e contribuem para um ambiente mais limpo e saudável (Leeuwen, Nijkamp, \& Vaz, 2010). Além disso, também Ihes permite fazerem face à pressão exercida pelos constantes aumentos de população urbana e aos impactos provocados pelas alterações climáticas, afigurando-se como formas de prover ambientes mais sustentáveis (World Health Organization, 2017). Acompanhando as transformações da cidade e da sociedade, as funções ambientais, sociais e culturais destes espaços têm variado ao longo do tempo, começando com as manifestações artísticas de alguns jardins, passando depois pelas áreas verdes das propriedades privadas das classes privilegiadas e culminando, a partir do século XVIII, na criação de grandes zonas verdes para usufruto da população (Mattos \& Constantino, 2019). 
Ao criarem estes espaços verdes, que bastante valorizam (Yilmaz \& Mumcu, 2016, p. 100), os planeadores das cidades procuram não só proporcionar aos seus utilizadores uma maior qualidade de vida e melhor saúde, mas também contribuir para a construção de certos imaginários como, por exemplo, o de cidade-verde ou cidade sustentável, reforçando a identidade das cidades, aumentando a sua capacidade de atração, contribuindo para a qualidade de vida e também para a sua competitividade, especialmente no caso das cidades de pequena e média dimensão (Leeuwen et al., 2010, p. 23). Em muitos casos, as apostas em determinados espaços verdes no interior da cidade, mesmo nos casos em que eles não são aproveitamentos do ambiente natural ali anteriormente existente, mas produções inteiramente artificiais feitas por ação humana, permitem que eles se tornem marcas ou postais-ilustrados dessas mesmas cidades. Desta forma, as zonas verdes urbanas são uma das componentes mais importantes, alterando a silhueta urbana e afetando a qualidade de vida física e psicológica dos seus habitantes (Yilmaz \& Mumcu, 2016, pp. 100-101).

\section{A pandemia da covid-19 em Portugal}

A facilidade de deslocamentos por via aérea e a difusa e ampliada conexão entre territórios amplificaram a velocidade de disseminação da covid-19, transportando o vírus com extrema rapidez para grandes centros urbanos de todo o globo e impelindo governos a recorrerem a ações drásticas de mitigação do contágio. Reconhecida como a medida mais eficiente para a prevenção da disseminação do vírus, o distanciamento social passou a ser adotado e, em algumas circunstâncias, imposto pelas autoridades. Em Portugal não foi diferente. Entre a confirmação do primeiro caso da doença em território português - a 2 de março de 2020 - e a entrada em vigor do Estado de Emergência, correram somente 17 dias, demonstrando a velocidade elevada de alastramento da doença e da urgência de respostas organizadas. Antes mesmo do decreto, no dia 13 de março, o governo português já emitira um diploma estabelecendo medidas "excecionais e temporárias" que procuravam acautelar a crise que se desenrolava.

Entre as medidas incorporadas no texto do Estado de Emergência, destaca-se o Artigo 5ㅇ, relativo ao "dever geral de recolhimento domiciliário", que propugnava a necessidade do distanciamento social e da permanência da população nas suas moradas sempre que possível. Além disso, com o decreto, passava a ser obrigatória a adoção do modelo de 
teletrabalho em todos os casos nos quais isso fosse possível e eram encerrados praticamente todos os estabelecimentos comerciais, de lazer, de cultura e de retalho, salvo aqueles considerados de primeira necessidade, que poderiam abrir as suas portas mediante a adoção de procedimentos de prevenção de contágio - tais como a redução e o controlo do número de clientes no interior dos estabelecimentos. O efeito foi logo sentido e o esvaziamento das ruas de diversos centros urbanos tornou-se manchete de diversos noticiários, com a maior parte da população de Portugal atendendo às exigências impostas. Dados já noticiados e consolidados (Fernandes, 2020) apontam que a adesão dos portugueses às medidas de isolamento social e auto-reclusão alcançou patamares substanciais. Mesmo com oscilações, houve períodos nos quais se registou que $79 \%$ da população não saiu de casa. Esse comportamento refletiu-se nas inúmeras fotografias que circularam, mostrando cidades, antes pulsantes e cheias de transeuntes, com ruas vazias, quase ou totalmente desertas. Com os espaços de lazer, trabalho e comércio fechados, e com restrições de encontros e reuniões em vigor, a permanência em casa - para aqueles que dispunham de um teto - por vezes era não só obrigação, mas a única opção por falta de outra escolha.

Nesse contexto, atividades individuais ao ar livre - principalmente passeios e exercícios físicos - pareceram ganhar projeção no período de confinamento e na sequência do desconfinamento ainda em andamento em Portugal. De forma convergente, num estudo realizado pela Faculdade de Medicina da Universidade do Minho durante a pandemia (Visão, 2020), constatou-se que indivíduos residentes em habitações com jardins acabaram por ter índices menores de stress, ansiedade e depressão: o espaço e o contacto com espaços arborizados e verdes demonstraram ser componentes importantes nesse processo.

\section{Condeixa-a-Nova e o parque verde de Ribeira de Bruscos: um}

\section{breve panorama}

A vila de Condeixa-a-Nova pertence ao distrito de Coimbra e integra a Região Centro de Portugal (NUTS II), inserindo-se na sub-região do Baixo Mondego (NUTS III), tendo uma área de cerca de $140 \mathrm{~km}^{2}$ (Ferreira, Peixoto, \& Silva, 2012). O concelho tem observado variações positivas de população residente, tendência invertida apenas nalgumas décadas e em linha com o que sucedeu nos restantes territórios da região (Mateus, 2009, p. 113), com destaque 
para os crescimentos de dois dígitos registados nos decénios 1991-2001 e 2001-2011, que coincidem com a expansão urbanística decorrente do surgimento de novas urbanizações, tornando-se um dos concelhos da zona centro com maior crescimento populacional constante nas últimas três décadas, cifrando-se a sua população, segundo os dados de 2018, em 17590 pessoas ${ }^{1}$.

Segundo os últimos Censos de 2011, mais de metade da população residente no concelho (56.1\%) situa-se na faixa entre os 25 e 64 anos, pelo que se conclui que se trata de uma vila com uma maioria de população em idade ativa Os idosos acima dos 65 anos representam cerca de vinte porcento $(19,2 \%)$ da população, e os jovens com menos de 24 anos cerca de um quarto nas freguesias centrais, valor que fica um pouco acima da média concelhia, que se situa pouco acima dos $20 \%$, pelo que se conclui estar-se perante um concelho jovem. 0 acréscimo de população fez com que aumentassem também os movimentos pendulares, assistindo Condeixa, segundo os Censos de 2011, a uma entrada diária no município de 1432 pessoas e a uma saída de 5847 (Instituto Nacional de Estatística, 2012), o que lhe confere uma das características fundamentais das cidades-dormitório, que é a de ter um maior número de saídas do que de entradas de pessoas.

O concelho de Condeixa-a-Nova integra, a par com Montemor-o-Velho, Soure, Miranda do Corvo, Poiares e Lousã, a constelação urbana de emprego presidida por Coimbra e assente nos serviços públicos proporcionados pela sua Universidade e pelos seus hospitais (Marques, 2006). Neste sentido, Condeixa funciona como dormitório de Coimbra, e isso tem implicações nos usos e na ligação ao lugar que os seus novos residentes mantêm com o local onde têm a sua residência principal. Num inquérito realizado para aferir a ligação ao lugar nas cidades-dormitório, e que teve por objeto a vila de Condeixa, constata-se que os seus residentes recorrem em percentagens significativas aos serviços públicos dos concelhos limítrofes em detrimento dos de Condeixa e $80 \%$ afirma não usar os espaços do concelho para efeitos de diversão (Soares, 2018). Ainda em relação a este estudo, quando questionados relativamente aos espaços de diversão frequentados à noite, a percentagem dos que responderam espaços verdes varia de um mínimo de 1,4\% (em conjugação com outros, como cafés ou restaurantes, por exemplo) e um máximo de $5,4 \%$, (no caso dos que

\footnotetext{
${ }^{1}$ Informação retirada de www.pordata.pt/Municipios/Quadro+Resumo/Condeixa+a+Nova-251590 , consultado em 23 de junho 2020.
} 
optaram pelos espaços verdes como escolha única (ibid.). Por estes dados, percebe-se que a utilização dos espaços de lazer e diversão na vila de Condeixa, especialmente no tocante aos espaços verdes, é muito reduzida.

A inauguração do Parque Verde da Ribeira de Bruscos/Sra. das Dores realizou-se a 22 de março de $2006^{2}$. Revisitando a notícia publicada no site da Câmara Municipal relativamente ao evento, percebe-se que ele é apresentado como sendo "a joia da coroa do Concelho", constituindo-se como uma "área paisagística privilegiada, dotada de valências consideradas revolucionárias em termos da região Centro", tratando-se de uma obra que representou cerca de 1,5 milhões de euros de investimento e cuja criação "foi norteada por preocupações com a requalificação urbana e equilíbrio ecológico de uma zona em franco crescimento" e que se pretendia vir a "proporcionar condições de bem estar e qualidade de vida aos cidadãos", sendo-Ihe atribuído várias valências que passaram pela construção de campos desportivos, mesas para merendas, zonas de manutenção física e dois jardins temáticos, um dedicado à cor e outro ao odor (Câmara Municipal Condeixa, 2006).

Nos dezasseis anos de existência com que conta o Parque Verde de Condeixa, tem-se assistido à atribuição de uma diversidade de funções, característica que parece ser uma marca inerente aos espaços verdes urbanos (Madureira, Nunes, Oliveira, \& Cormier, 2014; Madureira, Nunes, Oliveira, Cormier, \& Madureira, 2015). Esta multifuncionalidade é, aliás, uma das críticas que este tipo de espaços têm colhido, especialmente quando existe a conviç̧ão que ela é alcançada através da promoção de infraestruturas verdes sem que tenham de ser feitas escolhas entre funções (Leeuwen et al., 2010)

Uma consulta ao arquivo de notícias no site da Câmara Municipal de Condeixa relativo às atividades promovidas no Parque Verde, permite observar que este espaço albergou, desde a sua inauguração, as seguintes iniciativas: Festa da Família; Encontro de Jogos Tradicionais; o Spring Festival e respetivo acampamento de jovens; Corta Mato de Condeixa; Comemoração do Dia Mundial da Criança; Festa de Encerramento do Programa de

\footnotetext{
${ }^{2}$ Por Parque Verde Urbano entendemos "espaços verdes nos centros urbanos destinados a atender às necessidades humanas- como o lazer e a recreação- e que podem ter a sua natureza recriada (M. C. de L. Bezerra, Rocha, \& Bogniotti, 2016, p. 132).
} 
Mobilidade Sénior; Comemoração do Aniversário da Academia de Futsal; Taça de Portugal de Minigolfe; Dia Mundial do Ambiente; Dia Mundial da Árvore ${ }^{3}$.

\section{Métodos e procedimentos}

Para este artigo começou por proceder-se a uma análise de um conjunto de fotografias feitas no Parque Verde de Bruscos/Sra. das Dores, em Condeixa, nos meses de junho de 2019 e de 2020. Em ambos os anos, as fotografias foram tiradas durante uma semana no mesmo local e no horário compreendido entre as 18:30 e 19:30. Foi captada uma fotografia em cada um dos dias, sempre no mesmo local, por ele ser central e permitir obter uma maior cobertura do parque, permitindo captar a parte respeitante à zona de merendas, dos campos de jogos e do circuito de manutenção física que, habitualmente, concentram a maior parte dos frequentadores.

O primeiro conjunto de imagens foi obtido em sete dias no período compreendido entre os dias 21 e 30 de junho de $2019^{4}$. Todas as fotografias foram feitas ao final da tarde no intervalo de tempo já aludido e com condições atmosféricas de temperatura e humidade favoráveis à frequência do parque verde (temperatura amena e ausência de chuva). Da observação deste primeiro conjunto de fotografias, constata-se que em quatro dos sete dias havia utilizadores no parque, variando o seu número de um mínimo de duas pessoas (dia 24 junho) a um máximo de seis ( 28 de junho). Em três dias não houve visitantes à hora em que foram feitas as fotografias.

No que concerne ao segundo conjunto de fotografias, as sete imagens foram feitas entre os dias 4 e 10 de junho, tendo-se respeitado as mesmas regras utilizadas no conjunto anterior: fotografias feitas no mesmo intervalo e horário, com temperatura amena e com ausência de chuva. A análise deste segundo conjunto permite concluir que se observou a existência de visitantes em todos os sete dias documentados, presença que variou entre um mínimo de 4 pessoas no dia 6 de junho e um máximo de 9 em três dias diferentes (4, 9 e 10 de junho).

\footnotetext{
${ }^{3}$ Informação obtida no arquivo de notícias do site da Câmara Municipal de Condeixa através da pesquisa por Parque Verde, obtido em https://cm-condeixa.pt/pesquisa.php?q=parque+verde , consultado em 23 de junho de 2020.

${ }^{4} \mathrm{~A}$ ideia que presidiu a este primeiro conjunto de fotografias visava ser a base para um outro estudo (entretanto não realizado) que faria a comparação da utilização de um parque verde de uma vila dormitório com o de uma cidade capital de distrito.
} 
A análise destes dois conjuntos de fotografias (Figura 1) permitiu observar uma maior utilização do parque verde 2020 quando em comparação com 2019 (pré-pandemia), o que motivou a tentativa de procurar saber qual o impacto do confinamento decorrente da doença provocada pela covid-19 neste aparente maior afluxo de visitantes verificado. Importa, contudo, referir que, embora as fotografias tenham sido tiradas em ambos os anos no mesmo local e à mesma hora, não é possível concluir apenas com esta informação que o aumento de visitantes verificado é um indicador fidedigno de uma maior utilização do parque em 2020 quando comparado com o ano anterior, uma vez que, por um lado, o número de utilizadores observado é reduzido em ambos os anos, podendo levantar questões de representatividade, e, por outro, corresponde a apenas uma parte específica do dia, não permitindo perceber que frequência de utilização se verificou noutros momentos, como sejam a parte da manhã ou o período noturno, por exemplo. Para esclarecimento destas questões, optou por fazer-se um estudo quantitativo assente num inquérito a uma amostra da população de Condeixa-a-Nova que permitisse apurar qual o real impacto da pandemia na utilização do parque verde de Condeixa.
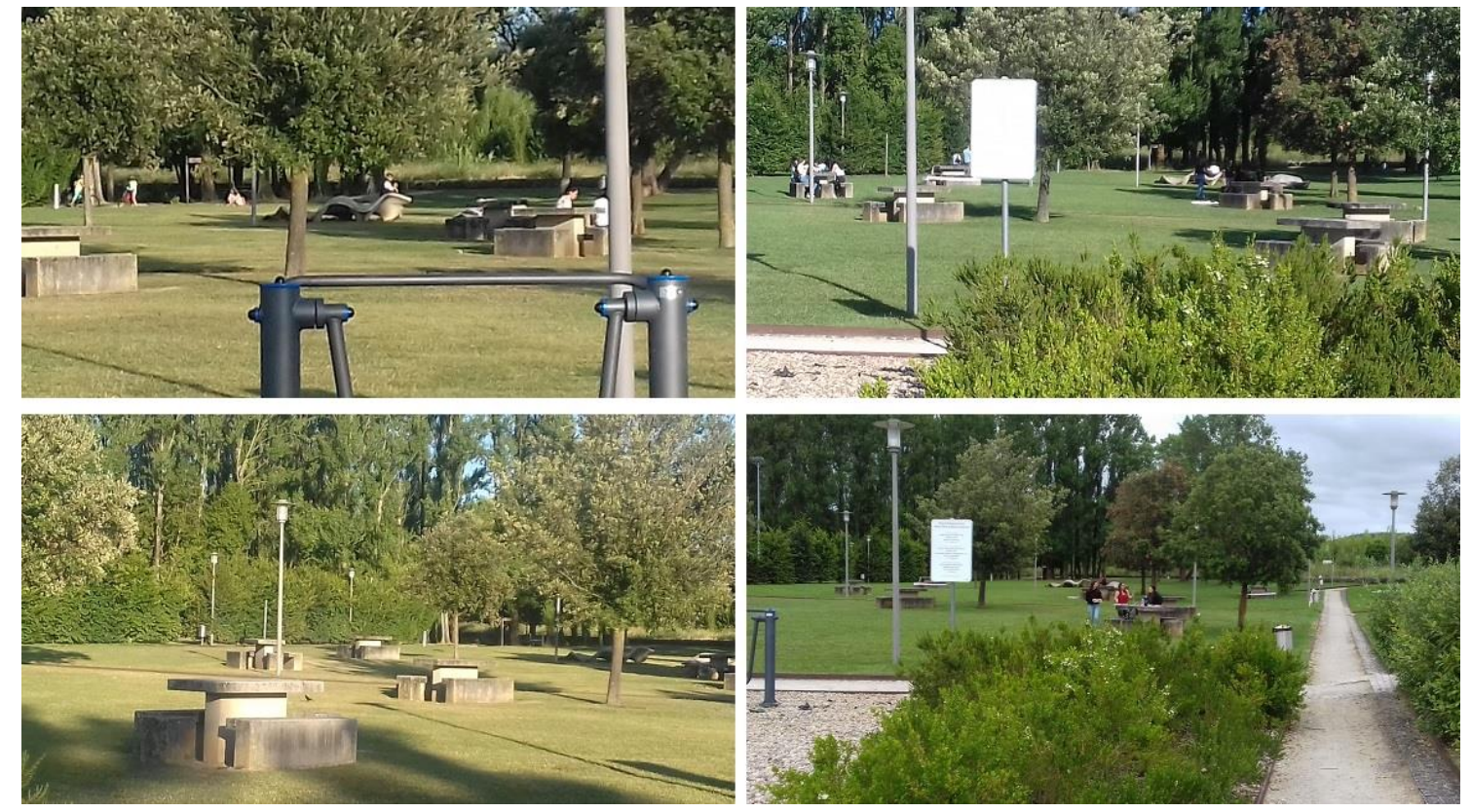

Figura 1: Em cima, da esquerda para a direita: registo fotográfico dos dias mais movimentados de 2019 e de 2020, respetivamente. Em baixo, da esquerda para a direita: registo fotográfico dos dias menos movimentados de 2019 e de 2020, respetivamente.

Fonte: elaboração própria 
O estudo foi feito com base num questionário construído na plataforma Google Forms constituído por dezasseis perguntas cuja disseminação foi feita por via eletrónica nas redes sociais Facebook e Whatsapp, o que permitiu obter uma amostra não probabilística constituída por 193 respostas.

O inquérito foi construído com base em três grupos de questões:

1- Retrato sociodemográfico da amostra;

2- Perfil de utilização do parque verde de Condeixa no período pré-pandémico, durante o confinamento e na fase de desconfinamento;

3- Razões da utilização e não utilização do parque verde e perspetivas de utilização futura após a pandemia.

O formulário de preenchimento eletrónico foi disponibilizado nas redes socias entre os dias 22 de junho de 2020 e 08 de julho de 2020, tendo sido obtidas 193 respostas. Efetuaram-se extrações de tabelas de frequências absolutas, no caso das questões respeitantes à caracterização sociodemográfica. Nos restantes dois grupos, além destas tabelas de frequências, foram também extraídas tabelas com cruzamento de variáveis. Tendo em conta que se trata de uma amostra não probabilística, os resultados obtidos devem ser vistos com as devidas cautelas, uma vez que podem estar contaminados de algum enviesamento decorrente do perfil-tipo do utilizador presente nas redes sociais onde o inquérito foi divulgado, como o caso da baixa representatividade dos indivíduos com mais de 65 anos observada na amostra parece indiciar, e que se pode dever à menor utilização destas ferramentas digitais por parte deste segmento da população.

\section{Análise dos resultados}

Os 193 inquéritos respondidos constituem uma amostra da população de Condeixa constituída por $57 \%$ de pessoas do sexo feminino e $43 \%$ do sexo masculino, sendo a faixa etária correspondente aos 35-44 anos a mais representada, concentrando $38,9 \%$ dos inquiridos. Outros dados sociodemográficos permitem perceber que $38,3 \%$ dos respondentes são trabalhadores por conta de outrem no setor privado, sendo o segundo grupo profissional mais representado o dos funcionários públicos com $24,4 \%$ das respostas. A grande maioria (63\%) exerce a sua atividade profissional fora do concelho de Condeixa, 0 
que é condizente com o perfil de uma vila dormitório como é o caso desta, e a maior parte dos inquiridos aufere um rendimento mensal inferior a $1000 €(39,9 \%)$ logo seguido do grupo dos que recebem entre $1000 €$ e $1500 €$ (29.5\%). Refira-se que, quando comprados os dados da amostra com os dados oficiais do último Censos 2011, o grupo dos indivíduos de 25-64 anos representa 77,5\%, acima, portanto, dos 56,1\% dos dados oficiais. Por outro lado, o grupo dos que têm mais de 65 anos é de apenas $2 \%$ na amostra, muito aquém dos 19,2\% obtidos nos Censos 2011, pelo que, mais uma vez, se chama a atenção para o facto de se estar a trabalhar aqui com dados decorrentes de uma amostra do tipo não probabilístico e alertar para as naturais limitações das ilações a retirar da sua leitura e interpretação.

Um segundo grupo de questões pretendia perceber qual o perfil de utilização do parque verde de Condeixa no período pré-pandémico, durante o confinamento e já na fase de desconfinamento. Para este exercício, optou por proceder-se ao cruzamento de variáveis que permitisse perceber as alterações de hábitos de utilização decorrentes da pandemia e a consequente declaração do estado de emergência nacional efetuado a 18 de março, e que esteve em vigor até ao dia 29 de abril.

Neste sentido, e após analisados os dados obtidos, constata-se, num primeiro momento, que quando questionados sobre qual a frequência com que utilizavam o parque verde de Condeixa antes do surgimento da pandemia (Figura 2), a opção mais escolhida foi a de "Algumas vezes ao ano", ou seja, uma utilização ocasional, com 26,4\%, logo seguida de "1-2 vezes por semana", escolhida por $20,7 \%$. Observando as respostas que se colocam em polos opostos (maior utilização e menor utilização), 11,9\% responderam frequentar o parque "Diariamente" e somente 5,7\% escolheram "1 vez ou menos vezes por ano". Ao agruparemse as opções de resposta em dois grupos (utilização regular e utilização ocasional), verificase que $41,4 \%$ dos inquiridos responderam que utilizavam o parque verde "1-2 vezes por semana", "3-5 vezes por semana" ou "Diariamente", o que indicia níveis de frequência, ainda assim, não despiciendos.

Com a declaração do estado de emergência, e consequente confinamento da população em casa, estando as deslocações não absolutamente necessárias e justificadas proibidas durante muitos dias, a frequência do parque verde diminuiu drasticamente, escolhendo 79,8\% dos inquiridos "Nunca" como opção de frequência do parque durante o 
confinamento (Figura 3). Já em período de desconfinamento (Figura 4), observa-se que voltou a verificar-se alguma utilização do parque verde, tendo a percentagem dos que afirmam na questão anterior ter ido "Nunca" descido de quase $80 \%$ durante o confinamento para $44,6 \%$ na fase de desconfinamento gradual.

Antes da Pandemia de COVID-19 frequentava o Parque Verde de Condeixa:

Diariamente

Mais de 1 vez por mês

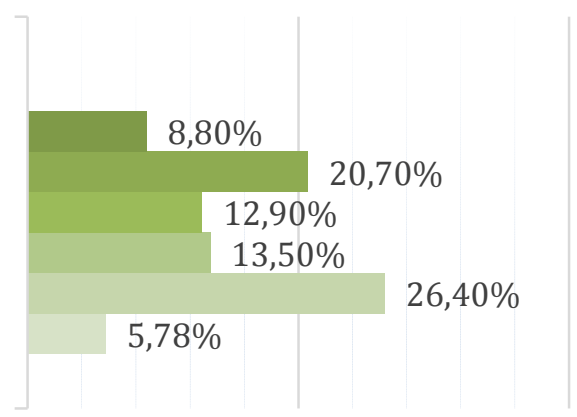

$0,00 \%$

$20,00 \%$

$40,00 \%$

$60,00 \%$

$80,00 \%$ $100,00 \%$

Figura 2: hábitos de frequência do parque verde de Condeixa antes da pandemia

Fonte: elaboração própria

Durante o período de confinamento decorrente da declaração do Estado de Emergência, utilizou o Parque Verde de Condeixa:

Diariamente

1-2 vezes por semana
3-5 vezes por semana $(0 \%)$

- Mais de 2 vezes durante o confinamento

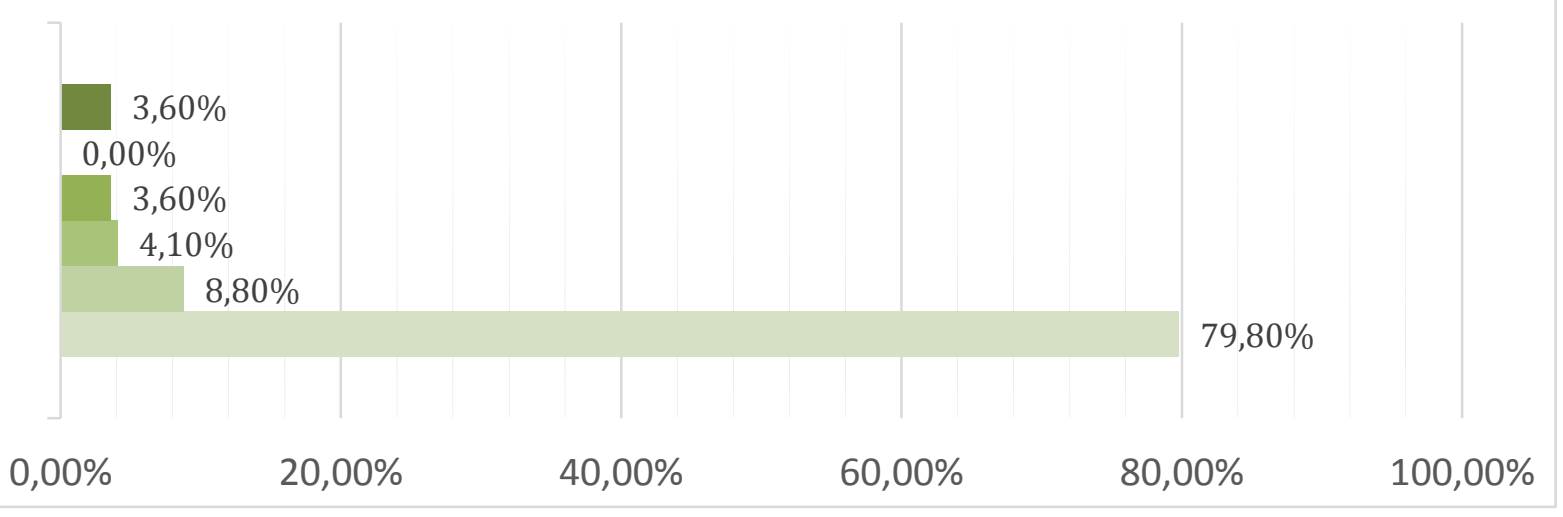

Figura 3: utilização do parque verde de Condeixa durante o confinamento obrigatório

Fonte: elaboração própria 
Na presente fase de confinamento, tem utilizado o Parque Verde de Condeixa:

\section{Diariamente}

Mais de 1 vez por mês

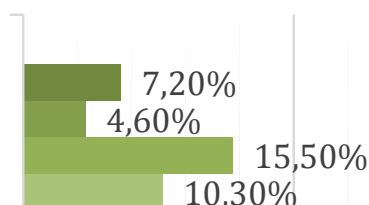

$10,30 \%$

$17,70 \%$

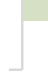

$0,00 \%$

$20,00 \%$
3-5 vezes por semana

1 vez por mês

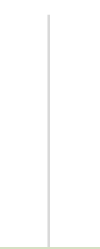

$44,60 \%$

$40,00 \%$

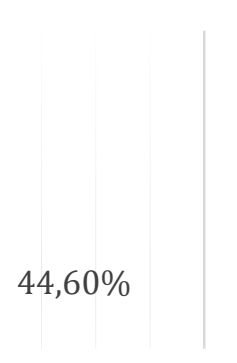

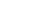

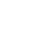

Nunca

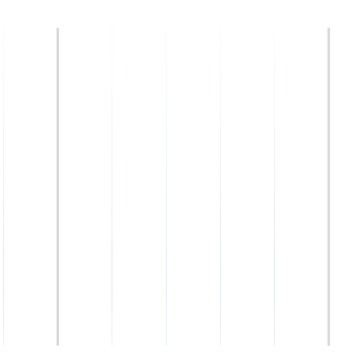

$80,00 \%$

$100,00 \%$

Figura 4: utilização do parque verde de Condeixa no atual período de desconfinamento

Fonte: elaboração própria

O cruzamento de variáveis deste grupo de questões permite obter um retrato mais claro das dinâmicas de frequência que se verificaram durante o período pré-pandémico, durante o confinamento e na fase de regresso à normalidade. Assim sendo, ao cruzar a variável frequência do parque na pré-pandemia com a que foi feita durante o confinamento, percebe-se que o grupo dos que eram frequentadores diários antes da chegada da doença foi o que maior utilização fez durante o confinamento, tendo todos os restantes (respostas acima de $75 \%$ ) optado por não frequentar o parque. Já quando se cruza a frequência prépandemia com o presente momento de desconfinamento, observa-se que aqueles que faziam uma utilização ocasional do parque ("1 vez ao ano ou menos" e "1 vez por mês") reduziram a sua frequência a zero, e os que afirmavam antes ir "Mais de uma vez por mês" passaram a ir maioritariamente apenas " 1 vez por mês". Nas restantes opções, relativas aos frequentadores habituais, verifica-se que a maior parte afirma frequentar o parque verde as mesmas vezes que antes do confinamento, embora se verifique igualmente uma tendência, por parte dos restantes inquiridos, para ir menos vezes que antes. Quando questionados se a utilização do parque verde no momento atual era maior, menor ou se se tinha mantido 
em relação ao período pré-pandémico, $50 \%$ afirmam que "Diminuiu" e apenas 14,9\% afirmam que ela "Aumentou".

Neste grupo de questões pretendeu-se também perceber qual a utilização do parque verde que os inquiridos faziam no período pré-pandémico em comparação com outros espaços de lazer como cafés, bares, ginásios, centros comerciais, etc. De acordo com as respostas obtidas (Figura 5), antes da pandemia a maior parte dos inquiridos $(37,2 \%)$ indicaram que "Utilizava mais o parque verde quando comparado com outros espaços". Colocada a mesma questão em relação ao momento atual (Figura 6), a opção mais escolhida foi "Utilizo mais o parque verde que outros espaços", sendo esta opção escolhida por 39,3\% dos inquiridos. Este dado levanta algumas questões, pois parece pouco verosímil que a população inquirida, especialmente quando mais de $77 \%$ se situa na faixa de idade compreendida entre os 25 e os 64 anos, afirme frequentar mais o parque verde do que cafés e outros espaços similares, nomeadamente quando foi possível observar in loco, quando se fizeram as fotografias para este estudo, que a cafetaria do museu PO.RO.S, espaço contíguo ao parque verde de Condeixa, tinha a esplanada com mais utilizadores que o parque. Isto poderá ser resultado do momento presente em que o país está ainda em modo de alerta devido à pandemia e em que nem todos os espaços, especialmente os espaços públicos em ambiente fechado, como os centros comerciais, se encontram já a funcionar ou fazem-no de forma muito condicionada, alterando os hábitos de frequência das pessoas, fazendo com que estas possam ter a perceção que a redução da utilização de, por exemplo, centros comerciais provocou um aumento de frequência de outros espaços, como os parques verdes. Assim sendo, a informação plasmada nos dados obtidos pelo inquérito não encontra total correspondência na observação que se pôde fazer no local em estudo. 


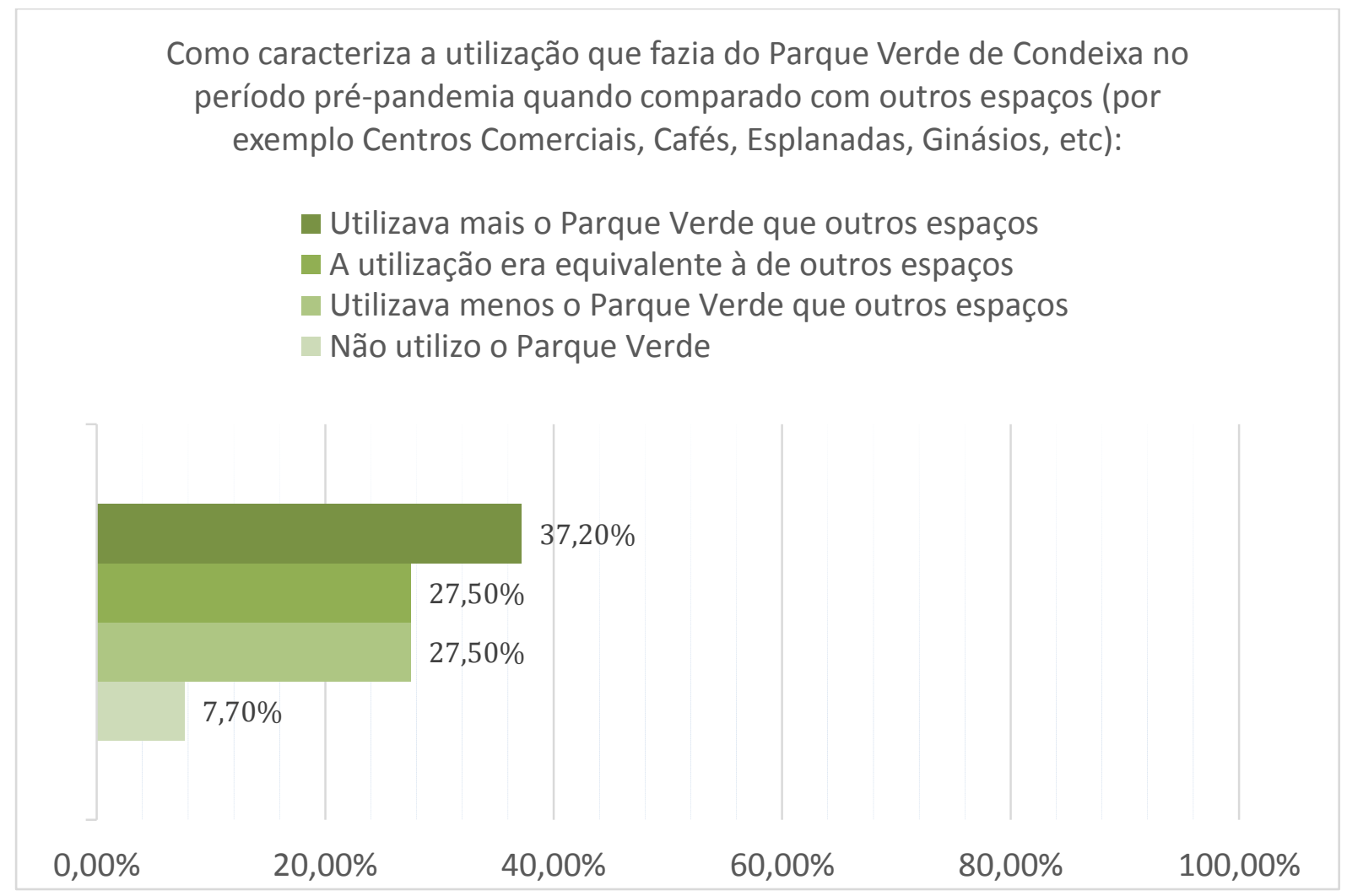

Figura 5: comparação da utilização do parque verde em relação a outros espaços antes da pandemia

Fonte: elaboração própria

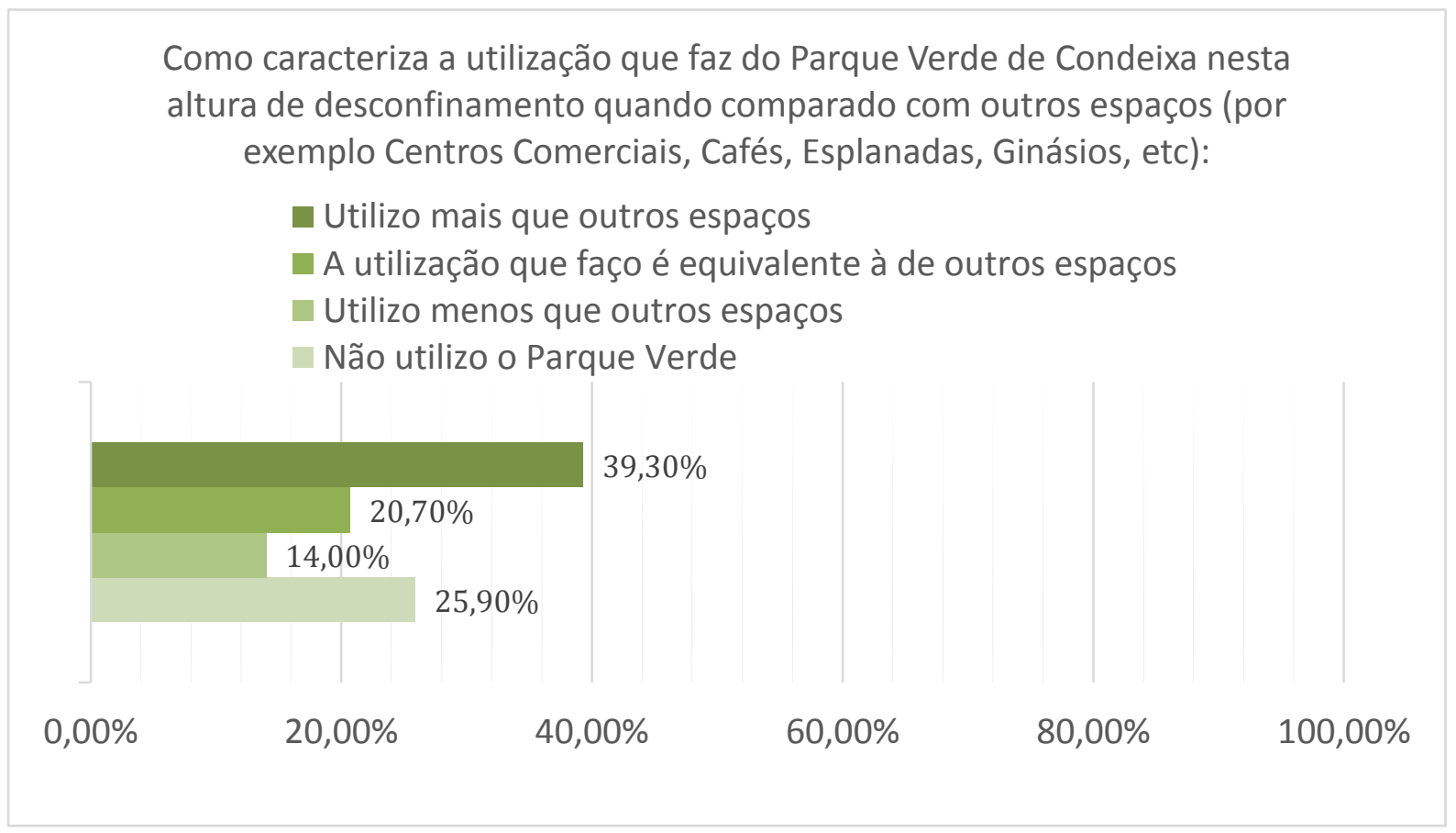

Figura 6: comparação dos níveis de utilização do parque verde em comparação com outros espaços no atual momento de desconfinamento

Fonte: elaboração própria 
Um último grupo de questões pretendeu aferir as razões que levam as pessoas a utilizar ou não o parque verde de Condeixa e procurar perceber quais as perspetivas de utilização após a pandemia. Desta forma, observa-se que as razões mais indicadas para frequentar aquele espaço são "Passear no parque" com 38,9\% e o "Convívio com familiares e amigos" com 32,1\%. Quando cruzada esta variável com as perspetivas de utilização futura do parque verde (Figura 7), a maioria dos inquiridos responde que "Penso utilizar o mesmo que antes", mas nos casos de quem escolheu como principal razão para frequentar o parque "Convívio com familiares e amigos", "Fazer piqueniques", "Passear no parque" e "Praticar exercício físico" cerca de um quarto afirma que pretende "Aumentar a frequência", com destaque para o caso dos que apontaram a opção "Fazer piqueniques" como principal razão para ir ao parque e onde se verifica que existem $36,3 \%$ de respostas que indicam que vão "Aumentar a frequência de utilização". Estes dados parecem indicar que o confinamento geral determinado pela pandemia motivou, de facto, uma alteração de comportamento conducente a maiores níveis de frequência do parque, como no caso daqueles que anteriormente à pandemia revelavam usar este espaço essencialmente para fazer piqueniques e que agora manifestam querer aumentar essa mesma utilização, depreendendo-se que o confinamento lhes provocou vontade de quererem recuperar o convívio social momentaneamente interrompido. Claro está que subsiste a dúvida de saber como se comportarão estes mesmos utilizadores quando, mais à frente, se entrar nas estações mais frias e menos convidativas para este tipo de utilização. 


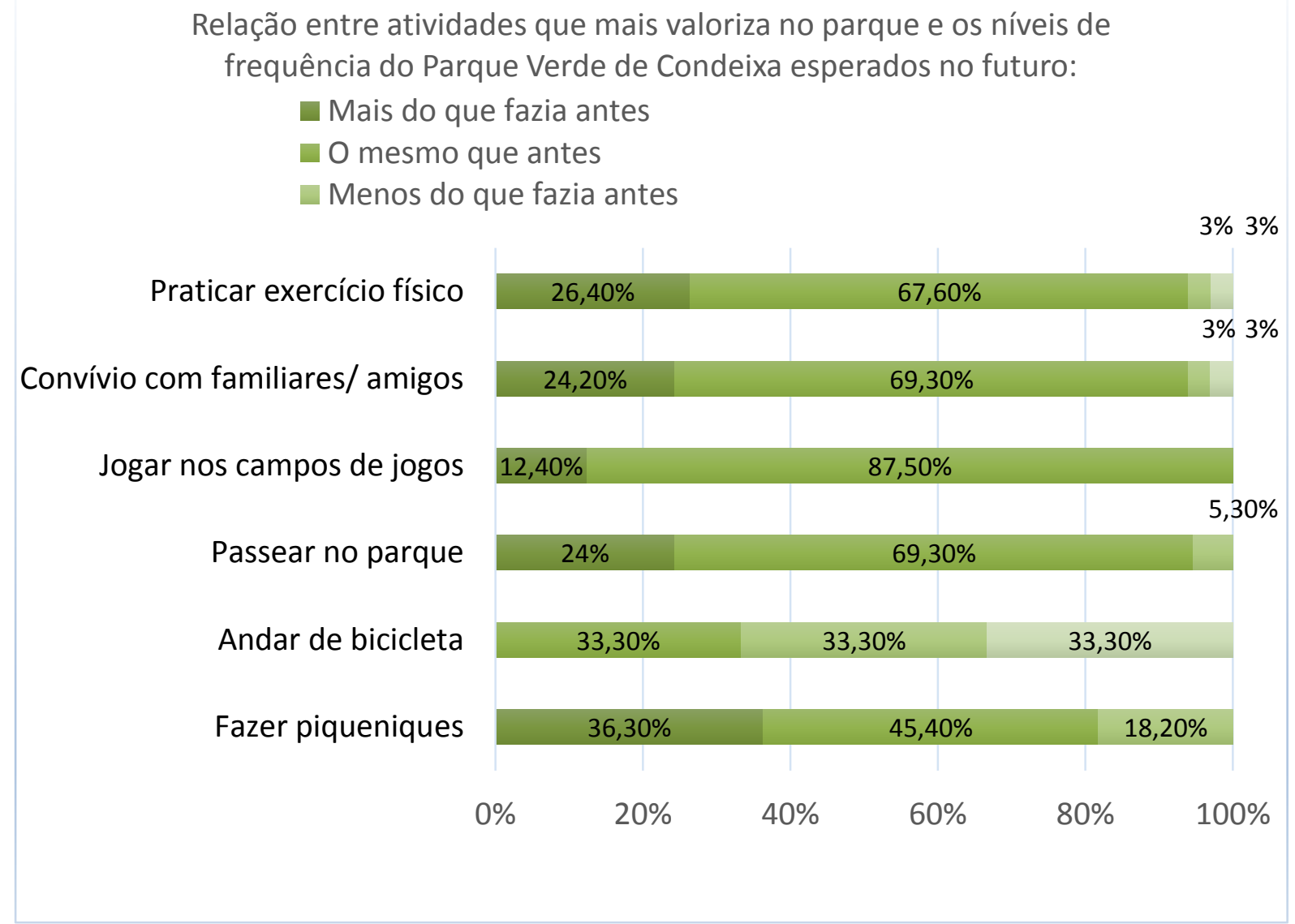

Figura 7: relação entre as atividades mais valorizadas no parque e os níveis de frequência esperados no futuro

Fonte: elaboração própria

No que respeita às razões apontadas para não utilizar mais vezes o parque verde, uma esmagadora maioria de 69,9\% apresenta como justificação a "Falta de tempo". Quando cruzada a variável que indica as "Razões para não frequentar mais vezes o parque verde" com a "Utilização no futuro" que pretendem fazer (Figura 8), a maioria responde que pensa manter o mesmo nível de utilização que antes, à exceção daqueles que apontaram como principal razão para não frequentarem este parque "Preferir ir a outros fora do concelho", informando a totalidade deste grupo de inquiridos que "Não tenciono utilizar o de Condeixa". De destacar ainda que mais de um quarto dos respondentes que compõem os grupos que apontaram "Desinteresse" e "Falta de tempo" como razões para não utilizarem mais este espaço pretendem utilizá-lo "Mais vezes do que fazia antes" (28,5\% e 27,9\%, respetivamente). Estes dados permitem concluir que, independentemente das razões apontadas anteriormente para não fazerem grande uso do parque verde, na maior parte 
dos casos os inquiridos pretendem manter os mesmos níveis de utilização, destacando-se o dado que aponta que a totalidade dos que afirmaram antes do confinamento não usar o parque verde da Ribeira de Bruscos, por preferirem frequentar outro parque, responderem que continuarão a não utilizá-lo.

\section{Relação entre as atividades mais valorizas no parque e interesse em frequentar ou não o Parque Verde de Condeixa no futuro:}

Mais do que fazia antes

O mesmo que antes

Menos do que fazia antes

Não penso frequentar o Parque Verde de Condeixa

Prefiro ir a outros parques fora de Condeixa

Prefiro ir a outros parques dentro do Concelho de Condeixa

Prefiro frequentar outros espaços de lazer

Falta de tempo

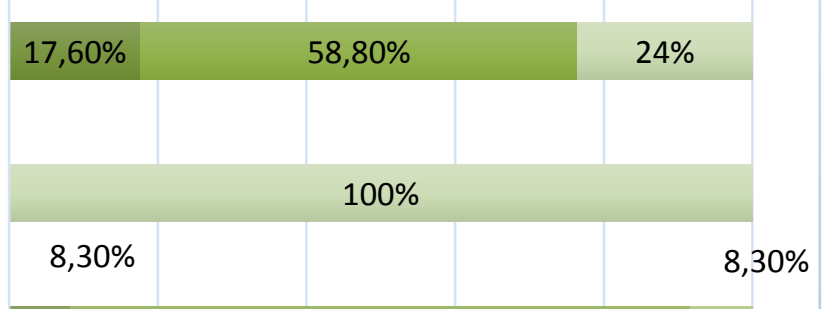

Pre

espaços de lazer

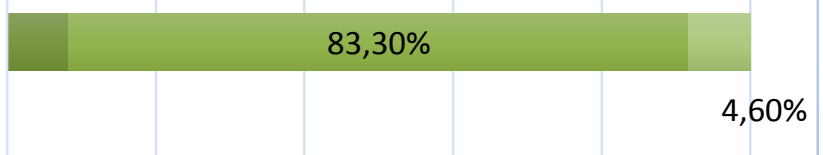

Desinteresse

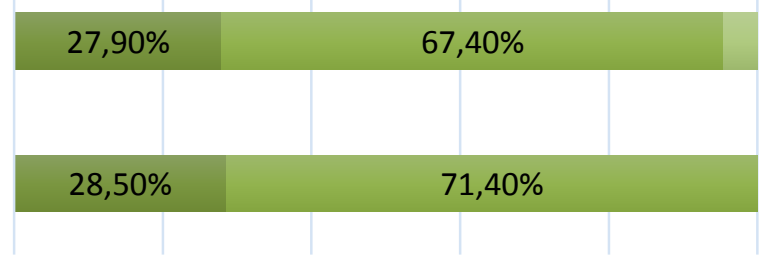

$0 \% \quad 20 \% \quad 40 \% \quad 60 \% \quad 80 \% \quad 100 \%$

Figura 8: relação entre frequentadores não habituais e interesse de utilização do parque no futuro Fonte: elaboração própria

A última questão colocada aos inquiridos pretendia saber que impacto o confinamento causado pela pandemia tinha exercido na vontade de estar em contacto com a natureza. Para $61,7 \%$ dos inquiridos o confinamento causou uma maior vontade, afirmando $35,2 \%$ que o impacto tinha sido nulo, pois a vontade mantém-se igual a de antes da pandemia". 


\section{Discussão dos resultados}

Este estudo partiu da perceção, obtida através da comparação de dois conjuntos de fotografias pertencentes a anos diferentes, que a frequência do parque verde urbano de Condeixa verificou um acréscimo de afluência no período pós-confinamento, avançando-se com a hipótese que o estado de emergência provocado pela covid-19 foi o responsável por esse maior afluxo. Desta forma, com este estudo, esperava apurar-se níveis baixos de frequência do parque verde de Condeixa no período pré-pandémico e assistir a um aumento significativo dessa utilização a partir do desconfinamento.

Os dados obtidos por via do inquérito feito a uma amostra da população residente traduzem-se em resultados algo inesperados. Se, por um lado, a frequência habitual do parque verde de Condeixa no período pré-covid revela valores acima do inicialmente previsto (cerca de 40\% afirmam, através das suas respostas, já serem utilizadores habituais antes do aparecimento da pandemia), já no que concerne à frequência de utilização declarada no período atual de desconfinamento o resultado fica aquém do percecionado, podendo até concluir-se por um decréscimo de utilização.

Numa primeira análise, o estudo quantitativo contraria a informação dos níveis de utilização do parque obtida através da comparação das fotografias entre os anos 2019 e 2020. Significa isso que, a confirmar-se a hipótese avançada no início do estudo, a percentagem de utilizadores habituais deveria situar-se atualmente em valores acima dos $40 \%$ apurados no período pré-pandemia. Contudo, esse valor cifra-se agora em cerca de $27 \%$, pelo que uma primeira conclusão é a de que o número de utilizadores habituais observou significativa redução com o surgimento da pandemia, e não um aumento - que progredisse a partir do período de desconfinamento -, como era esperado. Outro dado importante a reter em relação à comparação pré-pandemia com a fase de desconfinamento é a de que o número de inquiridos que afirma não utilizar o parque verde aumentou, mais uma vez contrariando aquilo que a análise fotográfica indiciava. Importa, como já referido, olhar para os dados obtidos através da observação das fotografias com o necessário distanciamento, tendo em conta as óbvias limitações em termos de representatividade que essa observação permite. 
Outra análise que importava fazer era a de apurar qual o nível de utilização do parque verde no período anterior à pandemia e o atual em comparação com o de outros espaços de lazer. Os dados recolhidos permitem perceber que se verifica uma ligeira subida na opção por utilizar o parque verde em detrimento de outros espaços de lazer (o que parece, mais uma vez não encontrar correspondência com observações feitas no local), mas o dado mais significativo resulta da informação que o número de inquiridos que afirma ter deixado de utilizar o parque verde ter aumentado significativamente, e isto indicia que o período atual - que obriga ainda a uma certa contenção nos contactos sociais e na própria mobilidade devido ao perigo de contágio pelo vírus da covid-19 - está ainda a manter parte considerável da população inquirida em casa.

Um último nível de análise incide sobre perspetivar a utilização futura que os inquiridos pensam fazer do parque verde urbano, e nesse aspeto cerca de um quarto das respostas indica que a utilização será maior do que a que se verificava antes da pandemia, ou seja, parece ser condizente com o argumento anteriormente sugerido que a utilização atual não é maior devido aos efeitos da situação pandémica que ainda se está a viver, antecipando-se que, no futuro, se verifiquem, de facto, maiores níveis de utilização do parque verde. A última questão do inquérito, que visava saber se o confinamento forçado tinha provocado um maior interesse em estar em contacto com a natureza, atesta isso mesmo, pois mais de $60 \%$ respondem afirmativamente a essa questão, concordando que essa vontade existe e foi potenciada pela obrigação de ter de ficar encerrado em casa durante as seis semanas do estado de emergência.

\section{Considerações Finais}

Diante dos dados obtidos, mais do que certezas surgiram novas questões, permitindo caracterizar este estudo como uma experiência exploratória bem-sucedida. Com a hipótese inicial fragilizada pelos resultados da análise, foi importante elaborar novas perguntas à realidade e aos próprios números para antecipar futuros rumos de investigação.

Entre as questões levantadas, uma perspetiva possível é a de que, apesar da redução geral no uso do parque pela maior parcela dos habitantes, o aparente aumento na presença de 
frequentadores refletiria a intensificação e o prolongamento no uso realizado por aqueles que já tinham por hábito ir ao parque. Contudo, um certo enviesamento que as informações resultantes deste inquérito podem trazer consigo questiona até que ponto esta possibilidade encontra ou não resposta clara e inequívoca por parte destes dados. Essa possibilidade mereceria uma investigação mais aprofundada - e envolveria contacto mais direto com os indivíduos, talvez um outro estudo, de abordagem eminentemente qualitativa, que se traduzisse em entrevistas, para um maior esclarecimento das dúvidas entretanto surgidas - mas ajuda a dar sentido à aparente incoerência percebida entre os resultados dos inquéritos e as fotografias obtidas em observações realizadas no campo. Esse exercício seria importante para poder complementar alguma da informação que, apenas com base neste inquérito, não nos parece suficiente para se poder afirmar com certeza que o confinamento determinado pela pandemia teve impactos concretos no comportamento da população de Condeixa-a-Nova, traduzindo-se num aumento de utilizadores do parque verde urbano.

Importa, ainda assim, destacar que uma parcela significativa dos inquiridos tem interesse em, no futuro, ter maior contacto com a natureza. Que natureza, seria a questão seguinte. Entender como esses indivíduos compreendem o "natural" e onde o encontram seria importante para perceber a própria relação que estabelecem com o parque verde e outros espaços públicos semelhantes. Para além disso, permitiria discutir o sentido mais lato que atribuem à ideia de natureza e como identificam os seus hábitos em relação a ela no contexto urbano, o que por si só é relevante diante da realidade antropocénica que se impõe a todos.

Cabe, como comentário final, a importância de reconhecer como a antropogénese alcançou tal patamar que hábitos alimentares num ponto do planeta são capazes de reverberar em mudanças de usos de espaços públicos a milhares de quilómetros de distância. As tramas que unem tão distintas localidades são por vezes tortuosas, mas não podem ser desprezadas e demonstra a diversidade escalar e o alcance das ações humanas sobre o globo, ressaltando a conectividade dos centros urbanos e a própria relação que têm com a natureza. 


\section{Referências Bibliográficas}

Bezerra, A., da Silva, C. M., Soares, F. R., \& da Silva, J. A. (2020). Fatores associados ao comportamento da população durante o isolamento social na pandemia de COVID-19. Ciência \& Saúde Coletiva, 25(Supl. 1), 24112421. https://doi.org/DOI: 10.1590/1413-81232020256.1.10792020

Bezerra, M. do C., da Rocha, M. A., \& Bogniotti, M. C. (2016). Qualidade dos espaços verdes urbanos: O papel dos parques de lazer e de preservação. arq.urb, (15), 128-142. https://doi.org/DOI: https://doi.org/10.37916/arq.urb.vi15.235

Brenner, N., \& Schmid, C. (2014). Planetary urbanization. Em Implosions/explosions: Towards a study of planetary urbanization (pp. 160-163). Berlin: Jovis Verlag.

Câmara Municipal Condeixa. (2006). Parque Verde inaugurado. A Câmara de Condeixa inaugurou um dos projectos mais emblemáticos ao nível de recuperação paisagística. Obtido de https://cmcondeixa.pt/noticia/15/

Fernandes, L. V. (2020). Portugueses saíram de casa depois da Páscoa. Taxa de isolamento passou de $79 \%$ para 56\%. Obtido 25 de Julho de 2020, de Observador website: https://observador.pt/2020/04/16/entre-54-e-79da-populacao-tem-ficado-em-casa-isolamento-bate-recorde-na-pascoa/

Ferreira, C., Peixoto, P., \& Silva, S. (2012). Estudo sobre Usos, Perceções e Necessidades de Acessibilidade e Mobilidade no Centro Urbano de Condeixa-a-Nova. APEUFEUC, Coimbra.

Fonseca, F., Gonçalves, A., \& Rodrigues, O. (2010). Comportamentos e percepções sobre os espaços verdes da cidade de Bragança. Finisterra, XLV(89), 119-139.

Instituto Nacional de Estatística. (2012). Censos 2011 Resultados Definitivos-Região Centro. Lisboa: INEInstituto Nacional de Estatística.

Leeuwen, E. van, Nijkamp, P., \& Vaz, T. de N. (2010). The multifunctional use of urban greenspace. International Journal of Agricultural Sustainability, 8(1-2), 20-25. https://doi.org/DOI: 10.3763/ijas.2009.0466

Madureira, H., Nunes, F., Oliveira, J. V., \& Cormier, L. (2014). Benefícios atribuídos aos espaços verdes urbanos pela população: Resultados de um inquérito conduzido em Lisboa e no Porto. Em F. M. C. Serdoura, R. A. R. Ramos, D. S. RodriguesL. C. L. de SouzaA. N. R. da Silva, L. C. L. de Souza, \& L. C. L. de SouzaA. N. R. da Silva (Eds.), (Re)Inventar a Cidade em tempos de mudança (pp. 2311-2321). Lisboa.

Madureira, H., Nunes, F., Oliveira, J. V., Cormier, L., \& Madureira, T. (2015). Urban residents beliefs concerning green space benefits in four cities in France and Portugal. Urban Forestry \& Urban Greening, 14, 56-64. https://doi.org/DOI: 10.1016/j.ufug.2014.11.008

Marques, T. S. (2006). Portugal urbano: Mosaicos, polaridades, relacionamentos e governança $=$ mosaicos, polaridades, relaciones e gobernanza. Em Cidade e democracia: 30 anos de transformação urbana em Portugal = Ciudad y democracia: 30 años de transformación urbana en Portugal (pp. 80-91). Lisboa: Argumentum.

Martin. (sem data). Cities. Obtido 19 de Outubro de 2020, de United Nations Sustainable Development website: https://www.un.org/sustainabledevelopment/cities/

Mateus, M. de L. R. (2009). Campos de Coimbra- Do Rural ao Urbano (Tese de Doutoramento). Universidade de Coimbra.

Mattos, K. A., \& Constantino, N. R. T. (2019). Benefícios dos espaços verdes urbanos: Valorização e avaliação pela população. GOT, Revista Eletrónica Centro de Estudos de Geografia e Ordenamento do Território, (16), 227-249. http://dx.doi.org/10.17127/got/2019.16.010

Soares, M. (2018). Cidades-Dormitório e Ligação ao Lugar: Um olhar sobre Condeixa-a-Nova (Dissertação de Mestrado). Universidade de Coimbra.

United Nations Department of Economic and Social Affairs. (2018). World Urbanization Prospects. New York: UN DESA's Population Division. 
Visão. (2020, Abril 14). Covid-19: Trabalho, exercício físico e jardim beneficiam saúde mental no isolamentoEstudo. Obtido 24 de Julho de 2020, de Visão website: https://visao.sapo.pt/visaosaude/2020-04-14-covid-19trabalho-exercicio-fisico-e-jardim-beneficiam-saude-mental-no-isolamento-estudo/

World Health Organization. (2017). Urban green spaces: A brief for action. Copenhagen: World Health Organization.

Yilmaz, S., \& Mumcu, S. (2016). Urban Green Areas and Design Principles. Em R. Efe, ì. Cürebal, A. Gad, \& B. Tóth (Eds.), Environmental Sustainability and Landscape Management (pp. 100-118). Sofia: St. Klement Ohridski University Press. 